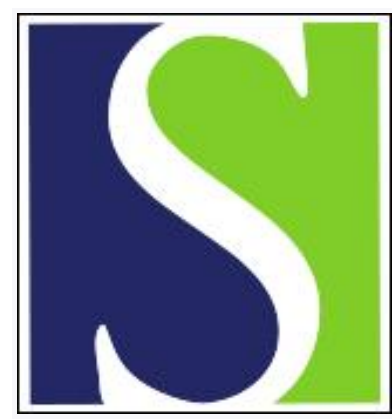

Scand J Work Environ Health 2002;28(5):314-323

https://doi.org/10.5271/sjweh.680

Issue date: Oct 2002

Impact of repetitive manual materials handling and psychosocial work factors on the future prevalence of chronic low-back pain among construction workers

by Latza U, Pfahlberg A, Gefeller O

Affiliation: Occupational Epidemiology, Insitute for Occupational Medicine, Hamburg State Department of Environment and Health, Adolph-Shoenfelder-Str. 5, D-22083 Hamburg, Germany. latza@uki.uni-hamburg.de

Refers to the following texts of the Journal: 1999;25(5):387-403 $1997 ; 23(4): 243-256$

The following article refers to this text: $2012 ; 38(3): 282-290$

Key terms: accelerated failure time; bricklayer; chronic low-back pain; cohort study; construction worker; musculoskeletal disease; occupational disease; prevalence; psychosocial work factor; repetitive manual materials handling; risk and rate advancement period; risk factor

This article in PubMed: www.ncbi.nlm.nih.gov/pubmed/12432984 


\title{
Impact of repetitive manual materials handling and psychosocial work factors on the future prevalence of chronic low-back pain among construction workers
}

\author{
by Ute Latza, PhD, ${ }^{1}$ Annette Pfahlberg, PhD, ${ }^{2}$ Oaf Gefeller, PhD ${ }^{2}$
}

\begin{abstract}
Latza U, Pfahlberg A, Gefeller O. Impact of repetitive manual materials handling and psychosocial work factors on the future prevalence of chronic low-back pain among construction workers. Scand $J$ Work Environ Health 2002;28(5):314-323.

Objectives This study investigated the influence of manual stone and brick handling and psychosocial work factors on the risk of chronic low-back pain and describes the impact in terms of risk advancement period.

Methods The Hamburg Construction Worker Study included a longitudinal study among 488 male construction workers. Adjusted prevalence ratios (PR) of chronic low-back pain ( $>3$ months during the last 12 months) according to self-reported worktasks in the baseline survey were estimated with the Cox proportional hazards model.

Results The 1-year prevalence of chronic low-back pain was $15.4 \%$. Workers with chronic low-back pain in the baseline survey had a higher risk of such pain during the follow-up (PR 4.07, 95\% CI 2.18-7.59). The prevalence in association with laying large lime sandstones for $>2$ hours per shift (PR 1.80, 95\% CI 1.04-3.14) further increased after adjustment for job category (PR 2.69, 95\% CI 1.25-5.78), and it advanced the risk by a risk advancement period of 18 years (95\% CI 4-39). Workers with low satisfaction with their work achievements had a higher prevalence of chronic low-back pain (PR 2.07, 95\% CI 1.10-3.88). Similar risk estimates were observed in the subgroup without chronic low-back pain in the baseline survey. A strong effect of time pressure was only present for these workers (high: PR 6.30, 95\% CI 1.41-28.21).

Conclusions The results suggest that repetitive work involving bent positions and the manual manipulation of heavy stones increases the risk of future chronic low-back pain. For risk communication, the notion that a $40-$ year-old construction worker laying large sandstones has the same risk as an unexposed 58-year-old construction worker may be more informative.
\end{abstract}

Key terms accelerated failure time, bricklayer, cohort studies, musculoskeletal diseases, occupational diseases, risk and rate advancement periods, risk factors.

There is evidence that physical workplace factors and probably psychosocial work factors contribute to the occurrence of low-back disorders (1-3). In industrialized countries, chronic low-back pain accounts for the majority of disability cases and the costs of occupational low-back pain $(4,5)$. In epidemiologic studies, chronic low-back pain has been characterized by the duration of symptoms (6).
In Germany, disc-related diseases of the lumbar spine due to the long-term lifting or carrying of heavy loads or on account of long-term activities requiring extreme trunk flexion were added to the list of occupational diseases in 1993. The statutory insurance funds for occupational accidents and diseases are responsible for the compensation for these diseases. In 1999, 11138 such claims ( $15 \%$ of the total number of claims) were

Occupational Epidemiology, Institute for Occupational Medicine, University of Hamburg and Hamburg State Department of Environment and Health, Hamburg, Germany. Department of Medical Informatics, Biometry, and Epidemiology, Friedrich-Alexander-University of Erlangen-Nuremberg, Germany.

Reprint requests to: Dr rer nat Ute Latza, Occupational Epidemiology, Institute for Occupational Medicine, Hamburg State Department of Environment and Health, Adolph-Schoenfelder-Str. 5, D-22083 Hamburg, Germany. [Email: latza@ uke.unihamburg.de] 
filed by the 42 million insured employees in the industrial sector (7). However, only 240 claims of subjects suffering from these low-back disorders $(1.4 \%$ of the total number of recognized claims) were recognized (7). About 33\% of the filed and recognized compensation claims came from the construction industry. This industrial sector is known to have a comparatively high prevalence of musculoskeletal disorders $(8,9)$. In a British study, the 1-year cumulative incidence of low-back pain was $40 \%$ for construction workers as compared with $28 \%$ for managers (10). Cross-sectional studies have suggested that bricklayers bear a particularly high risk for developing low-back pain (11) and low-back disorders (9). Longitudinal studies are needed to identify further the hazardous aspects of construction work with respect to low-back disorders in order to verify the occupational origin and to recommend and introduce effective preventive measures.

The cross-sectional baseline analysis of the Hamburg Construction Worker Study reports an increased risk for bricklayers (12). According to the longitudinal analysis, laying large lime sandstones was a potential risk factor for the 1-year prevalence of low-back pain in construction workers without low-back pain in the baseline survey (13) In the ergonomic evaluation that was part of the Hamburg Construction Worker Study, Grünwald et al (14) characterized the work of bricklayers as repetitive, involving the manipulation of heavy loads. Most of the observed activities of the bricklayers were carried out in a standing position (94.2\%). Thus more than $50 \%$ of their workhours were spent in a bent position. On the average, a bricklayer moved about 881 kilograms per hour. Handling lime sandstones was regarded as a comparatively strenuous task. A bricklayer doing piecework on a large construction site moved more than 1 tonne per hour when laying large lime sandstones.

A condition of the individual recognition of an occupational disease or the introduction of a new occupational disease in Germany or other countries is a probable occupational etiology. This condition has been translated into a probability of an occupational cause of more than $50 \%$, corresponding to a relative risk of 2 . The approach poses problems if the underlying disease prevalence is high in the general population. As a consequence, alternative measures to quantify the leftward shifting of disease onset have been suggested, similar to the model of years of life lost. The concept of the risk or rate advancement period (RAP) (15) has been used in recent studies $(16,17)$ to quantify the temporal advancement of the risk or rate of a chronic disease that increases with age.

In this article we report the risk of future chronic low-back pain associated with the manual handling of specific bricks or stones and the psychosocial work factors found in the entire cohort of the Hamburg Construc- tion Worker Study and in the subgroup without chronic low-back pain in the baseline survey. Furthermore, we estimated potential risk factors according to the risk advancement period to describe the impact of these factors on the timing of chronic low-back pain in exposed persons.

\section{Subjects and methods}

\section{Subjects}

The Hamburg Construction Worker Study is a longitudinal study initiated to identify risk factors of musculoskeletal disorders in the construction industry with a focus on bricklayers. The local ethics committee approved the study. Briefly, from May 1992 until December 1993, a sample of 571 male construction workers aged 17-59 years in the area of Hamburg, Germany, participated in the baseline survey, which has been described in detail earlier $(12,13)$. Out of this group, 371 employees were recruited from a routine health checkup (employer's liability insurance) and 108 from contact with local employers. As these employees were older than representative national samples of bricklayers, concrete builders, carpenters, and house painters from 1986, 32 employees were additionally signed up from vocational schools. During the first months of 1993, when recruitment was low, 60 subjects were approached through advertisements. Due to the mixed sampling frame, an overall participation rate was not determined. After 3 years, from May 1995 to July 1996, all the workers were approached for a follow-up survey. Altogether 488 could be traced and were willing to participate (follow-up $85.5 \%$ ). In previous analyses, younger age and a history of unemployment were associated with losses to follow-up (18).

\section{Chronic low-back pain}

During the structured interview, the participants were asked about the occurrence of low-back pain during the preceding 12 months ("Did you have pain in the lowback region during the last 12 months?"). Low back was defined as the lumbar spine and specified by an illustration, in case of ambiguity. If workers affirmed the question on low-back pain, further information about the type of pain was gathered. In the baseline interview, the interviewer asked several questions regarding the temporal pattern of different low-back pain types during the last 12 months. In the follow-up survey, only one question about the number of days with low-back pain during the last 12 months was included. Chronic low-back pain was defined as $\geq 90$ days of low-back pain during the last 12 months. Low-back pain lasting at least 90 
days in a row and low-back pain lasting at least 90 days within 1 year were not differentiated. Nonchronic lowback pain described low-back pain lasting less than 90 days during the last 12 months.

\section{Work factors and covariates}

In the baseline interview, questions were asked about age, smoking habits (pack-years), job title (carpenter, house painter, bricklayer, concrete builder, unskilled worker), and average daily hours of worktasks including laying six different kinds of bricks or stones during shifts in the preceding 12 months. Large lime sandstone (3DF) is a frequently used stone with a weight of about 6 to 10 kilograms - depending on the number and size of perforations. The size of $3 \mathrm{DF}$ stones is $50.0 \times 23.0 \times$ 10.4 (length $\times$ width $\times$ height, in centimeters). $2 \mathrm{DF}$ lime sandstone is smaller and weighs less $(4-6.5 \mathrm{~kg})$. The durations of laying 2DF and 3DF lime sandstones were highly correlated (Pearson correlation coefficient $\mathrm{r}=0.88$ ). Furthermore, the duration of laying clinker ( 0.8 to $1.4 \mathrm{~kg}), 2-3 \mathrm{DF}$ concrete blocks $(2.8-3.6 \mathrm{~kg})$, oversized (> 3DF) concrete blocks (> $3.6 \mathrm{~kg}$ ), and oversized lime sandstones $(>10 \mathrm{~kg})$ was requested. The reproducibility of the self-reported information on worktasks was good (19).

An index to measure the stone load (sum of average stone mass for each type of brick or stone multiplied by hours per day working with that stone type) and an index for laying oversized concrete blocks or sandstones normally weighing at least 10 kilograms and requiring both hands for gripping (yes;no) were compiled.

Psychosocial work factors that have been related to back pain and back disorders (20) were measured using a 5-point Likert scale (1=completely disagree, $2=$ disagree more or less, $3=$ partly agree, $4=$ agree more or less, $5=$ completely agree). They included monotonous work ["Altogether, my work is uniform (monotonous)"], time pressure ["I am under time pressure (lack of time is recorded)"], low job control ("Regulations and instructions hinder my performance very much"), poor social support ("Colleagues impede my work"), and satisfaction with own achievements at work ("I am satisfied with my achievements at work").

As in a previous analysis (13), worktask, the index of stone load, and psychosocial work factors were assigned to three categories according to the tertiles of their distribution among the 230 workers without low-back pain in the baseline survey. Anthropometric measures, sitting height in centimeters, and body mass index $\left(\mathrm{kg} / \mathrm{m}^{2}\right)$, were recorded during the orthopedic examination (12). Job change (yes;no) during the followup, reported by 75 workers, was considered a covariate.
Cumulative years of unemployment $(0 ; 1-17$ years), potential confounders, and potential risk factors were considered predictors of losses to follow-up.

\section{Data analysis}

Cox regression models were fitted to the data using the PHREG procedure of the SAS software (SAS Institute Inc, Gary, NC, USA) assuming a constant risk period (21). The dependent variable was the 1-year prevalence of chronic low-back pain (yes;no) during the follow-up. Prevalence ratios (PR) with 95\% confidence intervals (95\% CI) were calculated. The prevalence ratios were adjusted for age (years) and additional covariates as indicated. Confounding was reported if a change of more than $15 \%$ in the adjusted risk estimates occurred after additional adjustment for the covariates in separate models. A test for linear trend was analyzed with ordered categories of exposure. All the reported P-values are two-sided; those lower than 0.05 were considered significant.

The risk or rate advancement period has been proposed as an informative measure of risk factor impact on chronic disease occurrence (15). In essence, it quantifies the effect of risk factors on the timing of diseases that show a "natural" increase with age. The risk or rate advancement period must be interpreted with reference to the strength of the underlying age-incidence curve, because the magnitude of the risk advancement varies inversely to the strength of the age effect. For all diseases meeting the necessary assumptions, the risk or rate advancement period can be derived from the corresponding generalized linear model for the disease risk dividing the regression coefficient of the exposure (category) by the coefficient of age (15). Details of the technical realization of calculations of risk and rate advancement periods using the validated SAS macro RAPESTIM have been published (22). Several methods to quantify 95\% confidence intervals for ratio-type parameters like the risk and rate advancement periods have been suggested. In our study setting, characterized by rather few subjects in some of the exposure categories, we used the method based on the application of Fieller's theorem. This approach, originating from statistically related problems in bioassays (23), has been shown to be adequate even in cases of small sample sizes. The specific formula used to estimate the $95 \%$ confidence interval has been published elsewhere (24).

\section{Results}

Losses to follow-up were associated with age (PR 0.95, 95\% CI 0.92-0.98 per year), nonchronic low-back pain (PR 0.32, 95\% CI 0.17-0.60), high social support (PR 
$1.89,95 \%$ CI $1.00-3.57)$, and a history of unemployment (PR 2.30, 95\% CI 1.08-4.92) in the group without chronic low-back pain in the baseline survey. Similar results were obtained for the entire cohort (not shown).

The basic characteristics of the participants are shown in tables 1 and 2. By the end of the follow-up, 40 subjects had recovered from the chronic low-back pain episodes recognized in the baseline survey, and 31 new cases had occurred. The prevalence of chronic lowback pain in the entire cohort was higher in the baseline survey than in the follow-up survey.
Different pain characteristics of the subjects with chronic low-back pain were consistently higher at follow-up than in the baseline survey (table 3 ). Nearly all the subjects with chronic low-back pain in the followup survey had low-back pain during or after unusual movements or tasks. The subjects with nonchronic lowback pain often reported sudden attacks of low-back pain. Sciatic pain and long-lasting low-back pain were more common among the subjects with chronic lowback pain than among those with nonchronic low-back pain. The 1-year prevalence of low-back pain in the

Table 1. Personal characteristics of the workers without chronic low-back pain in the baseline survey and of all the workers at the time of the follow-up - Hamburg Construction Worker Study, 1992-1996. (SD = standard diviation)

\begin{tabular}{|c|c|c|c|c|c|c|c|c|c|c|c|c|c|c|c|}
\hline & \multicolumn{4}{|c|}{ Age (years) } & \multicolumn{4}{|c|}{ Smoking (pack-years) } & \multicolumn{3}{|c|}{ Body mass index $\left(\mathrm{kg} / \mathrm{m}^{2}\right)$} & \multicolumn{4}{|c|}{ Sitting height $(\mathrm{cm})$} \\
\hline & Median & nange & Mean & SD & Median & Range & Mean & SD & Median & Range & Mean SD & Median & Range & Mean & SD \\
\hline $\begin{array}{l}\text { Workers without chronic } \\
\text { low-back pain in the baseline } \\
\text { survey ( } N=404)\end{array}$ & 32 & 42 & 32.0 & 9.3 & 7.0 & 33.0 & 8.2 & 7.4 & 25 & 23 & 25.74 .2 & 95 & 32 & 94.8 & 3.7 \\
\hline $\begin{array}{l}\text { All workers with follow-up } \\
(\mathrm{N}=488)\end{array}$ & 31 & 42 & 33.1 & 10.0 & 7.5 & 33.0 & 8.7 & 7.7 & 25 & 23 & 25.84 .1 & 94 & 32 & 94.6 & 3.7 \\
\hline
\end{tabular}

Table 2. Job category and chronic low-back pain of the workers without chronic low-back pain in the baseline survey and of all the workers at the time of the follow-up - Hamburg Construction Worker Study, 1992-1996.

\begin{tabular}{|c|c|c|c|c|c|c|c|c|c|c|c|c|c|c|}
\hline & \multicolumn{10}{|c|}{ Job category } & \multicolumn{4}{|c|}{ Chronic low-back pain } \\
\hline & \multicolumn{2}{|c|}{ House painter } & \multicolumn{2}{|c|}{ Bricklayer } & \multicolumn{2}{|c|}{ Carpenter } & \multicolumn{2}{|c|}{ Concrete builder } & \multicolumn{2}{|c|}{ Unskilled worker } & \multicolumn{2}{|c|}{$\begin{array}{l}\text { In the baseline } \\
\text { survey }\end{array}$} & \multicolumn{2}{|c|}{$\begin{array}{l}\text { In the follow-up } \\
\text { survey }\end{array}$} \\
\hline & $\mathrm{N}$ & $\%$ & $\mathrm{~N}$ & $\%$ & $\mathrm{~N}$ & $\%$ & $\mathrm{~N}$ & $\%$ & $\mathrm{~N}$ & $\%$ & $\mathrm{~N}$ & $\%$ & $\mathrm{~N}$ & $\%$ \\
\hline $\begin{array}{l}\text { Workers without chronic } \\
\text { low-back pain in the } \\
\text { baseline survey ( } N=404)\end{array}$ & 115 & 28.5 & 150 & 37.1 & 63 & 15.6 & 54 & 13.4 & 22 & 5.5 & - & 0 & 31 & 7.7 \\
\hline $\begin{array}{l}\text { All workers with } \\
\text { follow-up (N=488) }\end{array}$ & 137 & 28.1 & 197 & 40.4 & 72 & 14.8 & 59 & 12.1 & 23 & 4.7 & 84 & 17.2 & 75 & 15.4 \\
\hline
\end{tabular}

Table 3. Selected back-pain characteristics in the baseline and follow-up surveys among the subjects with nonchronic low-back pain and chronic low-back pain - Hamburg Construction Worker Study, 1992-1996.

\begin{tabular}{|c|c|c|c|c|c|c|c|c|}
\hline \multirow[b]{3}{*}{ Back-pain characteristics } & \multicolumn{4}{|c|}{ Workers in the baseline survey $(\mathrm{N}=571)$} & \multicolumn{4}{|c|}{ Workers in the follow-up survey $(\mathrm{N}=488)$} \\
\hline & \multicolumn{2}{|c|}{$\begin{array}{l}\text { With nonchronic low-back } \\
\text { pain }(\mathrm{N}=185)\end{array}$} & \multicolumn{2}{|c|}{$\begin{array}{l}\text { With chronic low-back } \\
\text { pain }(\mathrm{N}=101)\end{array}$} & \multicolumn{2}{|c|}{$\begin{array}{l}\text { With nonchronic low-back } \\
\text { pain }\left(\mathrm{N}=168^{\mathrm{a}}\right)\end{array}$} & \multicolumn{2}{|c|}{$\begin{array}{l}\text { With chronic low-back } \\
\text { pain }(\mathrm{N}=75)\end{array}$} \\
\hline & $\mathrm{N}$ & $\%$ & $\mathrm{~N}$ & $\%$ & $\mathrm{~N}$ & $\%$ & $\mathrm{~N}$ & $\%$ \\
\hline Low-back pain during rest & 123 & 66.5 & 76 & 75.3 & 115 & 68.9 & 60 & 80.0 \\
\hline $\begin{array}{l}\text { Low-back pain during or after unusual } \\
\text { movements or tasks }\end{array}$ & 122 & 66.0 & 73 & 72.3 & 122 & 73.1 & 70 & 93.3 \\
\hline $\begin{array}{l}\text { Sudden attack of low-back pain } \\
\text { (lumbago) }\end{array}$ & 79 & 42.7 & 40 & 39.6 & 90 & 53.9 & 39 & 52.0 \\
\hline $\begin{array}{l}\text { Low-back pain radiating to the leg } \\
\text { (sciatic pain) }\end{array}$ & 55 & 29.7 & 49 & 48.5 & 60 & 36.9 & 40 & 53.3 \\
\hline Long-lasting low-back pain & 91 & 49.1 & 73 & 72.3 & 83 & 49.7 & 56 & 74.7 \\
\hline $\begin{array}{l}\text { Chronic low-back pain ( } \geq 90 \text { days of } \\
\text { low-back pain during the last } 12 \text { months) }\end{array}$ & 0 & 0 & 101 & 100.0 & 0 & 0 & 75 & 100.0 \\
\hline
\end{tabular}

a One subject with missing back-pain characteristics. 
baseline survey was associated with an increased risk of chronic low-back pain at the time of the follow-up survey in the entire cohort (PR 4.07, 95\% CI 2.18-7.59) and in the subgroup without chronic low-back pain in the baseline survey (PR 2.08, 95\% CI 1.01-4.29). The risk of chronic low-back pain at the time of the followup survey in association with chronic low-back pain in the baseline survey was even higher (PR 5.68, 95\% CI 3.46-9.32).

Potential risk factors of the 1-year prevalence of chronic low-back pain at the time of the follow-up were investigated for the entire cohort and for the subgroup without chronic low-back pain in the baseline survey (table 4). The risk increased monotonically with age in the entire cohort but not in the subgroup without chronic low-back pain. The age effect on the entire cohort was significant if age was considered a continuous variable (PR 1.05, 95\% CI 1.03-1.08 per 1 year). In the subgroup, the risk of chronic lowback pain at the time of the follow-up survey was lower in the age group between 40 and $<50$ years when this group was compared with the reference group (table 3 ).
In the subgroup, age had no significant effect if considered a continuous variable (PR 1.03, 95\% CI 0.99-1.07 per 1 year).

Psychosocial work factors showed a similar pattern in the entire cohort and in the subgroup without chronic low-back pain in the baseline survey (table 4). Low satisfaction with own achievements at work increased the risk of chronic low-back pain in the entire cohort. The test for linear trend was significant (table 4). A strong effect of time pressure on the 1-year prevalence of chronic low-back pain at the time of the follow-up survey was only found for the subgroup without low-back pain in the baseline survey. Adding covariates had no effect on the risk estimates of satisfaction with own achievements at work (not shown). Only the inclusion of the other psychosocial work factors decreased the risk estimate of low satisfaction with own achievements at work in the subgroup without chronic low-back pain in the baseline survey (medium: PR 1.51, 95\% CI 0.762.91; high: PR 1.53, 95\% CI 0.56-4.21).

The risk of chronic low-back pain at the time of the follow-up survey in association with laying 3DF lime

Table 4. Risk of chronic low-back pain at the time of the follow-up with respect to age and psychosocial work factors in the baseline survey among the workers without chronic low-back pain in the baseline survey and among all the workers - Hamburg Construction Worker Study, 1992-1996. ( $\mathrm{PR}=$ prevalence ratio, 95\% Cl =95\% confidence interval)

\begin{tabular}{|c|c|c|c|c|}
\hline & \multicolumn{2}{|c|}{$\begin{array}{l}\text { Workers without chronic low-back pain } \\
\text { in the baseline survey }(\mathrm{N}=404)\end{array}$} & \multicolumn{2}{|c|}{ All workers with follow-up ( $\mathrm{N}=488)$} \\
\hline & $\begin{array}{l}\text { Age-adjusted } \\
\text { PR }\end{array}$ & $95 \% \mathrm{a}$ & $\begin{array}{l}\text { Age-adjusted } \\
\text { PR }\end{array}$ & $95 \% \mathrm{a}$ \\
\hline \multicolumn{5}{|l|}{ Age } \\
\hline$<30$ years & 1 & Reference $^{a}$ & 1 & Reference ${ }^{a}$ \\
\hline $30-40$ years & 1.64 & $0.73-3.68$ a & 1.94 & $1.02-3.67$ a \\
\hline $40-<50$ years & 0.93 & $0.29-2.96$ a & 2.15 & $1.06-4.34$ a \\
\hline $50-<60$ years & 2.28 & $0.63-8.28$ a & 5.04 & $2.56-9.92^{a}$ \\
\hline \multicolumn{5}{|l|}{ Monotonous work } \\
\hline Low & 1 & Reference & 1 & Reference \\
\hline Medium & 1.39 & $0.58-3.36$ & 1.46 & $0.82-2.60$ \\
\hline High & 1.40 & $0.59-3.31$ & 1.50 & $0.86-2.62$ \\
\hline \multicolumn{5}{|l|}{ Time pressure } \\
\hline Low & 1 & Reference & 1 & Reference \\
\hline Medium & 7.43 & $1.70-32.57$ & 1.63 & $0.87-3.06$ \\
\hline High & 6.30 & $1.41-28.21$ & 1.70 & $0.92-3.15$ \\
\hline \multicolumn{5}{|l|}{ Job control } \\
\hline High & 1 & Reference & 1 & Reference \\
\hline Medium & 1.48 & $0.53-4.12$ & 1.45 & $0.71-2.96$ \\
\hline Low & 1.13 & $0.40-3.20$ & 1.39 & $0.69-2.83$ \\
\hline \multicolumn{5}{|l|}{ Social support } \\
\hline Low & 1 & Reference & 1 & Reference \\
\hline Medium & 1.39 & $0.58-3.36$ & 1.46 & $0.82-2.60$ \\
\hline High & 1.40 & $0.59-3.31$ & 1.50 & $0.86-2.62$ \\
\hline \multicolumn{5}{|c|}{ Satisfaction with own achievements at work } \\
\hline High & 1 & Reference & 1 & Reference ${ }^{b}$ \\
\hline Medium & 1.53 & $0.55-4.23$ & 1.67 & $0.88-3.13^{b}$ \\
\hline Low & 1.85 & $0.67-5.01$ & 2.07 & $1.10-3.88^{b}$ \\
\hline
\end{tabular}

a Age-adjustment not applicable.

${ }^{\mathrm{b}} \mathrm{P}=0.0402$, test for linear trend (Wald test). 
sandstones at the time of the baseline survey was increased and showed a dose-response relationship in the entire cohort (table 5). The test for linear trend was significant. The risk associated with laying 3DF sandstones for $>2$ hours per shift was higher in the subgroup without low-back pain in the baseline survey (table 5).

Adjustment for job category increased the strength of the association between laying large lime sandstones and chronic low-back pain and resulted in a stronger dose-response gradient (table 6). Higher prevalence ratios in association with laying 3DF sandstones also appeared in the subgroup without chronic low-back pain (>0-<2 hours/shift: PR 0.81, 95\% CI 0.14-4.57; 2-8.5 hours/shift: PR 4.66, 95\% CI 1.36-16.00). Other covariates did not confound the associations between laying 3DF sandstones and chronic low-back pain at the time of the follow-up survey (table 6), except for other psychosocial work factors in the subgroup without chronic low-back pain. They increased the risk estimate of the highest exposure category (2-8.5 hours/shift: PR $3.70,95 \%$ CI 1.64-8.33). Other individual factors (body mass index, sitting height, smoking) did not confound the associations (not shown). Job changes between the baseline and follow-up surveys did not influence the risk estimates. However, the highest category of stone load became significant in the subgroup without chronic lowback pain in the baseline survey after job changes were included in the model (PR 2.24, 95\% CI 1.01-4.97).

The risk advancement period, interpretable in this presentation as the length of the time period in which exposed workers have the same risk of developing chronic low-back pain earlier in their life than unexposed workers, can be adequately estimated. That of the highest exposure category for laying large lime sandstones was more than 10 years in all the analyses (table 6). Similar to the observed effects of covariates on the risk estimates, the inclusion of job category in the model increased the estimate of the risk advancement period for laying 3DF sandstones for $>2$ hours/shift to 17.8 years $(95 \%$ CI $4.0-39.1)$.

\section{Discussion}

The study population of the Hamburg Construction Worker Study was not a random sample of all construction workers in Hamburg. However, the age distribution of

Table 5. Risk of chronic low-back pain at the time of the follow-up survey with respect to job category and work factors of the bricklayers in the baseline survey among the workers without chronic low-back pain in the baseline survey and among all the workers - Hamburg Construction Worker Study 1992-1996. (PR = prevalence ratio, 95\% Cl =95\% confidence interval)

\begin{tabular}{|c|c|c|c|c|}
\hline & \multicolumn{2}{|c|}{$\begin{array}{l}\text { Workers without chronic low-back pain } \\
\text { in the baseline survey ( } \mathrm{N}=404)\end{array}$} & \multicolumn{2}{|c|}{ All workers with follow-up ( $\mathrm{N}=488$ ) } \\
\hline & $\begin{array}{l}\text { Age-adjusted } \\
\text { PR }\end{array}$ & $95 \% \mathrm{Cl}$ & $\begin{array}{l}\text { Age-adjusted } \\
\text { PR }\end{array}$ & $95 \% \mathrm{Cl}$ \\
\hline \multicolumn{5}{|l|}{ Job category } \\
\hline House painter & 1 & Reference & 1 & Reference \\
\hline Bricklayer & 1.25 & $0.49-3.19$ & 0.93 & $0.52-1.64$ \\
\hline Carpenter & 1.45 & $0.45-1.60$ & 1.23 & $0.59-2.57$ \\
\hline Concrete builder & 1.31 & $0.38-4.47$ & 0.61 & $0.23-1.64$ \\
\hline Unskilled worker & 2.21 & $0.57-8.57$ & 0.86 & $0.25-2.88$ \\
\hline \multicolumn{5}{|l|}{ 2DF lime sandstone } \\
\hline 0 hours/shift & 1 & Reference & 1 & Reference \\
\hline$>0-<2.0$ hours/shift & 0.87 & $0.29-2.57$ & 0.78 & $0.39-1.54$ \\
\hline $2.0-8.5$ hours/shift & 1.98 & $0.80-4.89$ & 1.45 & $0.80-2.62$ \\
\hline \multicolumn{5}{|l|}{ 3DF lime sandstone } \\
\hline 0 hours/shift & 1 & Reference & 1 & Reference $^{a}$ \\
\hline$>0-<2.0$ hours/shift & 0.50 & $0.12-2.14$ & 1.13 & $0.59-2.16^{a}$ \\
\hline 2.0-8.5 hours/shift & 2.89 & $1.32-6.35$ & 1.80 & $1.04-3.14^{\mathrm{a}}$ \\
\hline \multicolumn{5}{|l|}{ Stone load } \\
\hline Low & 1 & Reference & 1 & Reference \\
\hline Medium & 0.57 & $0.17-1.96$ & 0.63 & $0.31-1.30$ \\
\hline High & 2.10 & $0.95-4.65$ & 1.44 & $0.85-2.46$ \\
\hline \multicolumn{5}{|l|}{ Laying $>3$ DF stones } \\
\hline No & 1 & Reference & 1 & Reference \\
\hline Yes & 1.88 & $0.81-4.39$ & 0.98 & $0.51-1.86$ \\
\hline
\end{tabular}

a $\mathrm{P}=0.0476$, test for linear trend (Wald test). 
Table 6. Influence of covariates on the prevalence ratio (PR) and risk advancement period (RAP) for laying large (3DF) lime sandstone - Hamburg Construction Worker Study, 1992-1996, N=488. (95\% Cl=95\% confidence interval)

\begin{tabular}{|c|c|c|c|c|c|}
\hline Work factor & Covariates & PR & $95 \% \mathrm{Cl}$ & RAP & $95 \% \mathrm{Cl}$ \\
\hline Laying 3DF sandstone & Age (years) & & & & \\
\hline 0 hours/shift & & 1 & Reference a & 0 & Reference \\
\hline$>0-<2.0$ hours/shift & & 1.13 & $0.59-2.16^{\text {a }}$ & 2.5 & $-10.6-19.2$ \\
\hline $2.0-8.5$ hours/shift & & 1.80 & $1.04-3.14^{a}$ & 11.9 & $0.7-31.0$ \\
\hline Laying 3DF sandstone & Age (years) \& occupation (5 job categories) ${ }^{b}$ & & & & \\
\hline 0 hours/shift & & 1 & Reference $^{c}$ & 0 & Reference \\
\hline$>0-<2.0$ hours/shift & & 1.66 & $0.72-3.83^{c}$ & 9.2 & $-6.1-28.3$ \\
\hline $2.0-8.5$ hours/shift & & 2.69 & $1.25-5.78^{c}$ & 17.8 & 4.0-39.1 \\
\hline Laying 3DF sandstone & $\begin{array}{l}\text { Age (years) \& low-back pain in the baseline } \\
\text { survey (yes; no) }\end{array}$ & & & & \\
\hline 0 hours/shift & & 1 & Reference $^{d}$ & & Reference \\
\hline$>0-<2.0$ hours $/$ shift & & 1.10 & $0.57-2.10^{d}$ & 2.4 & $14.6-26.1$ \\
\hline $2.0-8.5$ hours/shift & & 1.71 & $0.98-3.00^{d}$ & 3.6 & $-0.5-45.0$ \\
\hline Laying 3DF sandstone & $\begin{array}{l}\text { Age (years) \& psychosocial work factors } \\
\text { (low; medium; high) }\end{array}$ & & & & \\
\hline 0 hours/shift & & 1 & Reference $^{f}$ & 0 & Reference \\
\hline$>0-<2.0$ hours/shift & & 1.29 & $0.66-2.51^{f}$ & 3.6 & $-9.7-21.3$ \\
\hline 2.0-8.5 hours/shift & & 1.88 & $1.05-3.37^{f}$ & 10.6 & $-0.9-31.7$ \\
\hline
\end{tabular}

a $\mathrm{P}=0.0476$, test for trend (Wald test). [From table 4]

${ }^{b}$ House painter, bricklayer, carpenter, concrete builder, unskilled worker.

c $P=0.0104$, test for linear trend (Wald test).

${ }^{\mathrm{d}} \mathrm{P}=0.0760$, test for linear trend (Wald test).

e Monotonous work, time pressure, job control, social support, satisfaction with own achievements at work.

f $\mathrm{P}=0.0346$, test for linear trend (Wald test).

the bricklayers in the baseline survey was comparable with two representative, occupation-based samples of German bricklayers aged $18-50$ years and examined in 1992 and 1993 (data not shown). The prevalence of chronic low-back pain at the time of the follow-up $(15.4 \%)$ was lower than the prevalence in the baseline survey (17.7\%). This decrease in spite of the observed age effect on chronic low-back pain within the cohort, the increasing age during follow-up, and the low percentage of withdrawals indicates selection bias. Although chronic low-back pain in the baseline survey was not a significant predictor of losses to follow-up (PR $1.58,95 \%$ CI $0.92-2.71$ ), it can be assumed that some workers with chronic low-back pain had been lost from the follow-up.

The longitudinal analysis of the Hamburg Construction Worker Study was conducted with a 3-year lag in time between the exposure and the 1-year prevalence of chronic low-back pain. The cases of chronic lowback pain consisted of both incident and recurrent (or chronic) cases. The transition from low-back pain to chronic low-back pain is probably influenced by psychosocial, socioeconomic, and clinical factors apart from occupational factors (25). In order to separate etiologic factors of low-back pain from predictors of the recurrence or chronification of low-back pain, relative risk estimates were additionally shown for the subgroup without chronic low-back pain in the baseline survey.
History of low-back pain, two psychosocial factors (satisfaction with own achievements at work, time pressure), and a physical work factor (laying large lime sandstones) were predictors of future chronic low-back pain. The results were similar in the entire cohort and in the subgroup without chronic low-back pain in the baseline survey, except for differences regarding age, laying 3DF lime sandstones, and time pressure. The findings are consistent with previous findings according to which a history of low-back pain (25-31) proved to be important, whereas height, weight, and probably smoking habits were not associated with back disorders in occupational populations (32).

Low satisfaction with own achievements at work increased the risk in the entire cohort. In other prospective studies, low job satisfaction influenced future lowback pain or disorders (26-28, 33-35). It is questionable whether job dissatisfaction is a separate psychosocial characteristic or a stress symptom due to work conditions that can modify the relation between a risk factor and low-back pain $(3,20)$. In a recent prospective study of transit operators (36), job dissatisfaction was a predictor of work-related spinal injury even after control for past physical workload. Time pressure was a potential risk factor in the group without chronic lowback pain but not for the 84 workers with chronic lowback pain in the baseline survey (data not shown). As time pressure was not associated with an enhanced risk of future low-back pain in an earlier analysis (13), this 
psychosocial work factor may be the most important for the incidence of chronic low-back pain but not for its persistence or aggravation. The subjects with chronic low-back pain in both surveys were more exposed to low levels of time pressure than those who reported chronic low-back pain only at the time of the follow-up (data not shown). This finding may imply self-selection out of worktasks with high time pressure or minor importance for time pressure after the occurrence of chronic low-back pain. More research on the influence of psychosocial work factors on the incidence of chronic lowback pain is required.

The risk of laying large lime sandstones weighing about 7-10 kilograms was mostly independent of the effect of psychosocial work factors. Laying large lime sandstones showed a dose-response relationship in the entire cohort, particularly after adjustment for occupation. The risk increased with higher levels of exposure. If the models were additionally adjusted for occupation, there was a twofold increase in the risk of chronic lowback pain for a workload of at least 2 hours per shift in the entire cohort and in the group without chronic lowback pain. The results may be interpreted so that being a bricklayer alone has a lower risk than being a bricklayer who lays large lime sandstones. Medium levels of this work factor and of the other ones of the bricklayers investigated were associated with no risk (or a marginally enhanced one). The fact that this finding particularly applied to the group without chronic low-back pain in the baseline survey implies either a beneficial effect of a comparatively short exposure and particularly unfavorable work conditions when hard work is done over a long time during the shift or selective losses of moderately exposed workers who later develop chronic low-back pain in the follow-up survey. The exposure to high levels of laying large lime sandstone (>2 hours/shift) and to handling oversized stones (>3DF) was comparatively rare among the subjects with chronic low-back pain in the baseline survey and who also reported chronic low-back pain at the time of the follow-up (data not shown). This finding indicates that heavily exposed subjects may have changed to less strenuous worktasks due to their back problems. As a consequence, these risk estimates were lower in the entire cohort in the group without chronic low-back pain in the baseline survey even after control for job changes.

The evidence that laying heavy stones is a potential risk factor for low-back pain has been shown in previous analyses of the Hamburg Construction Worker Study (13) and can be based on coherence with the ergonomic evaluation (14) and with other findings regarding physical work factors $(14,28,33,32,37-41)$. The previously reported risk of future low-back pain in association with laying large lime sandstones in the group without low-back pain in the baseline survey was comparable, although lower than the risk estimate reported in this analysis (13). Grünwald et al (14), who monitored construction workers for the Hamburg Construction Worker Study, characterized the work of bricklayers as repetitive and involving frequent work in bent or awkward positions and the manipulation of heavy loads. Due to confidentiality regulations, ergonomic data could not be combined with the epidemiologic study. Physical work factors were associated with incident low-back pain $(28,37)$, and care seeking for low-back pain (33) in prospective studies on British nurses (37) and Dutch workers doing hard physical work (28) and in a population-based study in Sweden (33). In a Dutch inception cohort, the risk associated with frequent bending during work was doubled for patients with chronic symptoms as compared with those with nonchronic symptoms (38). In recent studies, cumulative physical workload was assessed by new monitoring methods (39-41). In a study in the American automobile industry, trunk flexion and lifting at work were identified as risk factors for back disorders (39). In a prospective cohort study among several Dutch companies, flexion of the trunk and lifting at work were identified as risk factors of lowback pain (41).

Risk and rate advancement periods quantify the period in which the risk or rate of a chronic disease is advanced or delayed among exposed people in the absence of competing risks $(15,22,24)$. A fundamental assumption for the application of the concept of the risk or rate advancement period is the existence of a monotonous relationship between the outcome and age. The entire cohort of the Hamburg Construction Worker Study revealed a monotonous age effect on chronic low-back pain risks. The risk advancement period was not calculated for the group without chronic low-back pain in the baseline survey because the workers of the group aged 43-53 years at the time of the follow-up had a lower risk than the reference age group; this finding indicates a nonmonotonous age effect, perhaps due to selection bias.

A further prerequisite for the application and interpretation of the concept of the risk advancement period is a causal association between exposure and disease. Given that laying large lime sandstones is a potential causal risk factor, we employed the risk advancement period and derived (for the first time) estimates of the risk advancement period in an occupational setting. That a 40-year-old construction worker laying large lime sandstones has the same risk of chronic low-back pain after 3 years as an unexposed 62-year-old construction worker provides useful information for risk communication. As the age effect on chronic low-back pain was moderate and as the risk advancement periods were computed with reference to the underlying age incidence curve, the estimation of the risk advancement 
period in this situation resulted in high values. When risk advancement periods are interpreted, it should be kept in mind that the estimates are not only sensitive to bias in the exposure-outcome association (as are all epidemiologic effect measures), but also in the age-outcome association. Therefore, underestimating the true age effect due to some form of selection bias that may be operating in the presented study will lead to an overestimation of the risk advancement periods. A more precise quantification of the associated risk advancement periods by a future larger study on this topic carefully addressing potential selection bias is needed. Regarding mortality, it is accepted that a life-span of $\geq 1$ years is important. The further application of the approach to measure the accelerated failure time of chronic diseases in association with work factors will lead to a better interpretation of the observed advancement associated with the repetitive manual handling of heavy stones.

This study could not detect moderately increased risks. Given the study size and the low prevalence of chronic low-back pain, there was considerable imprecision in many of the estimates; in other words the confidence intervals were wide for exposures with low prevalence and risk estimates of $<2.5$ (eg, the risk estimates of laying 2DF lime sandstones). Moreover, a conservative approach was taken with the used Cox proportional hazards model, which produces standard errors that are too large (21). In addition, we used a method for quantifying the precision of the risk advancement periods that guarantees valid confidence intervals (ie, those holding the nominal confidence levels of $95 \%$ even in case of sparse data). The price typically to be paid for the application of this procedure is an asymmetric widening of the confidence intervals as compared with those derived by standard asymptotic procedures like the delta method (15).

In conclusion, the presented results suggest that time pressure and a physical work factor characterized by repetitive work in bent positions, as well as the manipulation of heavy stones, increase the risk of developing chronic low-back pain. The estimates for the risk advancement periods of laying large lime sandstones shown in this presentation translate the impact of this potential risk factor into time periods that may be better understood by exposed workers and thus play an important role in the process of risk communication.

\section{Acknowledgments}

The study was supported by a grant from the German Federal Ministry for Research and Technology (BMBF Nr HG019/1). Annette Pfahlberg was additionally sup- ported by a grant from the Deutsche Forschungsgemeinschaft (grant Ge 637/3-1,3-2,3-3).

We would like to thank the construction workers for their participation, the employer's liability insurance (Bau-Berufsgenossenschaft Hamburg) and the employers for their efforts in the recruitment of participants, and also Karin Weber for reviewing the language of the manuscript.

\section{References}

1. Bernard BP, editor. Musculoskeletal disorders and workplace factors: a critical review of epidemiologic evidence for work-related musculoskeletal disorders of the neck, upper extremity, and low back. Cincinnati $(\mathrm{OH})$ : US Department of Health and Human Services, National Institute for Occupational Safety and Health, 1997. DHHS (NIOSH) publication, no $97-141$.

2. Hoogendoorn WE, van Poppel MNM, Bongers PM, Koes BW, Bouter LM. Physical load during work and leisure time as risk factors for back pain. Scand J Work Environ Health 1999;25:387-403.

3. Hoogendoorn WE, Poppel MNM, Bongers PM, Koes BW, Bouter LM. Systematic review of psycosocial factors at work and private life as risk factors for low back pain. Spine 2000;25:2114-25.

4. Frank JW, Kerr MS, Brooker A-S, DeMaio SE, Maetzel A, Shannon HS, Sullivan TJ, Norman RW, Wells RP. Disability resulting from occupational low back pain. Spine 1996;21:2908-17.

5. Guo H-R, Tanaka S, Halperin WE, Cameron LL. Back pain prevalence in US industry and estimates of lost work days. Am J Public Health 1999;89:1029-35.

6. Cedraschi C, Robert J, Goerg D, Perrin E, Fischer W, Vischer TL. Is chronic non-specific low back pain chronic?: definitions of a problem and problems of a definition. Br J Gen Prac 1999;49:358-62.

7. Hauptverband der gewerblichen Berufsgenossenschaften (HVBG). BG Statistics: figures and long-term trends 1999. St. Augustin (Germany): HVBG, 2000.

8. Murphy PL, Courtney TK. Low back disability: relative costs by antecedent and industry group. Am J Ind Med 2000;37: 558-71.

9. Rothenbacher D, Brenner H, Arndt V, Fraisse E, Zschenderlein B, Fliedner TM. Disorders of the back and spine in construction workers: prevalence and prognostic value for disability. Spine 1997;22:1481-86.

10. Macfarlane GJ, Thomas E, Papageorgiou AC, Croft P, Jayson MIV, Silman AJ. Employment and physical work activities as predictors of future low back pain. Spine 1997; 22: 1143-49.

11. Holmström E, Lindell J, Moritz U. Low back and neck/ shoulder pain in construction workers; occupational work load and psychosocial factors, part 1: relation to low back pain. Spine 1992;17:663-71.

12. Stürmer T, Luessenhoop S, Neth A, Soyka M, Karmaus W, Toussaint R, et al. Construction work and low back disorder: preliminary findings of the Hamburg construction worker study. Spine 1997;22:2558-63.

13. Latza U, Karmaus W, Steiner M, Neth A, Stürmer S, Rehder 
U. Cohort study of occupational risk factors of low back pain in construction workers. Occup Environ Med 2000; 57:2834.

14. Grünwald C, Becker G. Fleischer AG. Arbeitsbelastung und zeitliche Struktur der Bauarbeit [Work load and temporal structure of skilled manual work]. Z Arbeitswiss 1998; 4: 250-9.

15. Brenner H, Gefeller O, Greenland S. Risk and rate advancement periods as measures of exposure impact on the occurrence of chronic disease. Epidemiology 1993; 4:856-72.

16. Stevens J, Cai J, Juhaeri, Thun MJ, Williamson DF, Wood JL. Consequences of the use of different measures of effect to determine the impact of age on the association between obesity and mortality. Am J Epidemiol 1999;150:399-407.

17. Liese AD, Hense HW, Brenner H, Lowel H, Keil U. Assessing the impact of classical risk factors on myocardial infarction by rate advancement periods. Am J Epidemiol 2000;152: $884-8$.

18. Latza U, Karmaus W, Rehder W. Wer scheidet aus der Studie aus?: Befunde aus der Hamburger Bauarbeiter-Studie [Who is lost to follow up?: Results from the Hamburg Construction Worker Study] [abstract]. In: Michaelis J, Himmel G, Kaatsch P, Krummenauer F, Oferloch B, Pommerening K, et al, editors. Proceedings of 44th Biometrisches Kolloquium der Deutschen Region der Internationalen Biometrischen Gesellschaft and the 6th National Meeting of the Deutsche Arbeitsgemeinschaft Epidemiologie, Kurzfassung der Beiträge, Deutsche Arbeitsgemeinschaft Epidemiologie, Mainz, Germany 1998:P33. Mainz: Deutsche Region der Internationaler Biometrisches Gesellschaft, Deutsche Arbeitsgemainschaft Epidemiologie, 1998.

19. Latza U, Karmaus W, Steiner M. The reproducibility of selfreported information on work tasks and pain [abstract]. In: Finnish Institute of Occupational Health, Scientific Committee on Musculoskeletal Disorders, editor. Proceedings of the 13th International Symposium on Epidemiology on Occupational Health and the 3rd International Scientific Conference on Prevention of Work-Related Musculoskeletal Disorders (PREMUS-ISEOH '98), Abstracts. Helsinki: Finnish Institute of Occupational Health, 1998:52.

20. Bongers PM, de Winter CR, Kompier MAJ, Hildebrandt VH. Psychosocial factors at work and musculoskeletal disease. Scand J Work Environ Health 1993;19:297-312.

21. Skov T, Deddens J, Petersen MR, Endahl L. Prevalence proportion ratios: estimation and hypothesis testing. Int $\mathrm{J}$ Epidemiol 1998;27:91-5.

22. Pfahlberg A, Gefeller O, Brenner H: Computational realization of point and interval estimation of risk and rate advancement periods. Epidemioliology 1995;6:99-100.

23. Fieller EC. A fundamental formula in the statistics of biological assays and some applications. Q J Pharm Pharmacol 1944;17:117-23.

24. Pfahlberg A, Gefeller O. Assessing the impact of classical risk factors on myocardial infarction by rate advancement periods. Am J Epidemiol 2001;154:486-8.

25. Valat JP, Goupille P, Vedere V. Low back pain: risk factors for chronicity. Rev Rhum Engl Ed 1997;64:189-94.

26. Feyer A-M, Herbison P, Williamson AM, de Silva I, Mandryk J, Hendrie L, Hely MCG. The role of physical and psychosocial factors in occupational low back pain: a prospective cohort study. Occup Environ Med 2000;57:116-20.

27. Papageorgiou AC, Croft PR, Thomas E, Ferry S, Jayson MI,
Silman AJ. Influence of previous back pain experience on the episode of low back pain: results from the South Manchester Back Pain Study. Pain 1996;66:181-5.

28. van Poppel MNM, Koes BW, Devillé W, Smid T, Bouter LM. Risk factors for back pain incidence in industry: a prospective study. Pain 1998; 77:81-6.

29. Verbeek JH, van der Beek AJ. Psychosocial factors at work and back pain: a prospective study in office workers. Int $\mathbf{J}$ Occup Med Environ Health 1999; 12:29-39.

30. Riihimäki H. Viikari-Juntura E, Moneta G, Kuha J, Videman $\mathrm{T}$, Tola $\mathrm{S}$. Incidence of sciatic pain among men in machine operating, dynamic physical work, and sedentary work - a three-year follow up. Spine 1994;19:38-142.

31. Müller CF, Monrad T, Biering-Sørensen, Darre E, Deis A, Kryger P. The influence of previous low back trouble, general health, and working conditions on future sick-listing because of low back trouble. Spine 1999;24:1562-70.

32. Burdorf A, Sorock G. Positive and negative evidence of risk factors for back disorders. Scand J Work Environ Health 1997;23:243-56.

33. Vingård E, Alfredsson VE, Hagberg M, Kilbom A, Thoeorell T, Waldenström M, Hjelm EW, Wiktorin C, Hogstedt C. To what extent do current and past physical and psychosocial occupational factors explain care-seeking for low back pain in a working population?: results from the Muskuloskeletal Intervention Center-Norrtälje Study. Spine 2000; 25:493500 .

34. Thomas E, Silman AJ, Croft PR, Papageorgiou AC, Jayson MI, Macfarlane GJ. Predicting who develops chronic pain in primary care: a prospective study. BMJ 1999;318:1662-7.

35. Papageorgiou AC, Macfarlane GJ, Thomas E, Croft PR, Jayson MI, Silman AJ. Psychosocial factors in the workplace do they predict new episodes of low back pain?: evidence from the South Manchester Back Pain Study. Spine 1997;22: $1137-42$.

36. Krause N, Ragland DR, Fisher JM, Syme SL. 1998 Volvo Award Winner in clinical studies: psychosocial job factors, physical workload, and incidence of work-related spinal injury: a 5-year prospective study of urban transit operators. Spine 1998;23:2507-16.

37. Smedley J, Egger P, Cooper C, Coggon D. Prospective study of predictors of incident low back pain in nurses BMJ 1997; 314:1225-8.

38. Miedema HS, Chorus AMJ, Wevers CWJ, van der Linden S. Chronicity of back problems during working life. Spine 1998; 23:2021-9.

39. Punnett L, Fine LJ, Keyserling WM, Herrin GD, Chaffin DB. Back disorders and nonneutral trunk postures of automobile assembly workers. Scand J Work Environ Health 1991;17: $337-46$.

40. Norman R, Wells R, Neumann P, Frank J, Shannon H, Kerr M. A comparison of peak vs cumulative physical work exposure risk factors for the reporting of low back pain in the automotive industry. Clin Biomech (Bristol, Avon) 1998;13: 561-73.

41. Hoogendoorn WE, Bongers PM, de Vet HCW, Douwes M, Koes BW, Miedema MC, et al. Flexion and rotation of the trunk and lifting at work are risk factors for low back pain. Spine 2000;25:3087-92.

Received for publication: 1 October 2001 